\title{
SURVEILLANCE OF VETERINARY DRUG RESIDUES IN PORK MEAT IN MADAGASCAR ${ }^{\ddagger}$
}

\author{
SURVEILLANCE DES RÉSIDUS DE MÉDICAMENTS VÉTÉRINAIRES \\ DANS LA VIANDE PORCINE À MADAGASCAR
}

\section{VIGILANCIA DE RESIDUOS DE MEDICAMENTOS VETERINARIOS EN CARNE DE CERDO EN MADAGASCAR}

\author{
M. Rakotoharinome ${ }^{1}$ D. Pognon ${ }^{2}$ T. Randriamparany ${ }^{3}$ \\ J. Chane Ming ${ }^{4}$ J.-P. Idoumbin ${ }^{4}$ E. Cardinale ${ }^{5}$ V. Porphyre ${ }^{2 *}$
}

\begin{abstract}
ntibiotics are used in animal feeds as growth promoters Aor for disease prevention and treatment. Drugs and their metabolites accumulate into body cells and constitute the socalled drug residues. Residual antimicrobials in food are an increasing risk for human health. Antibiotic residues in meat and other foods are suspected to be responsible for drug allergies and emergence of antimicrobial-resistant bacteria.

In Madagascar, bacterial resistance against several antibiotics has been regularly observed in pathogens isolated from humans and pigs. Suspicion of drug misuse in farms has been frequently recorded by animal health professionals but no guidelines are available on the good usage of antibiotics in livestock. Since scarce information is available on antimicrobial residues in animal products in Madagascar, this study aimed at determining the prevalence of pork meat contaminated by such residues and sold in Antananarivo markets.
\end{abstract}

A total of 967 meat samples (diaphragm muscle) were collected during 2010 and 2011 in the four main abattoirs of Antananarivo, and in three additional regional abattoirs, i.e. Antsirabe, Mahitsy

1. Direction des Services vétérinaires de Madagascar, ministère de l'Elevage, rue Farafaty Ampandrianomby, Antananarivo, Madagascar.

2. Cirad, UMR Selmet, station de Ligne-Paradis, 7 chemin de l'IRAT, 97410 Saint-Pierre, Réunion, France.

3. Laboratoire national de diagnostic vétérinaire, ministère de l'Elevage, Antananarivo 102, Madagascar.

4. Centre de recherche et de veille sur les maladies émergentes dans l'océan Indien, Cyroi, 97491 Sainte-Clotilde Cedex, Réunion, France.

5. Cirad, UMR Cmaee, 2 rue Maxime Rivière, BP 80005, 97491 Sainte-Clotilde Cedex, Réunion, France.

* Corresponding author

E-mail: vincent.porphyre@cirad.fr

$\$$ This text summarizes an oral communication presented at QualiREG Scientific Days in 2012. Since then, full results have been published as a research article (Rakotoharinome et al., 2014) (1).
(Central Madagascar) and Tsiroamandidy (Western Madagascar). Analysis for antimicrobial detection in meat was performed with the commercial Premi®-test kit (DSM, Urmond, Netherlands) at the National Veterinary Diagnostic Laboratory in Antananarivo. Premi ${ }^{\circledR}$-test is a broad spectrum microbial screening test for the detection of antibiotic and sulfonamide residues in meat or meat products at, or below maximum residue limit (MRL) levels. MRL is the maximum concentration of residues following administration of a veterinary medicine which is legally permitted or acceptable in food under European Union legislation. The Premi $\circledR$-test kit contains a standardized number of spores of Bacillus stearothermophilus, very sensitive to many antibiotics and sulfa compounds, in agar medium with selected nutrients together with an indicator. Premi®-test is based on the inhibition of the growth of $B$. stearothermophilus. When meat juice is added to the Premi®-test ampoule and heated at $64^{\circ} \mathrm{C}$, spores germinate. The germinated spores multiply and form an acid when no inhibitory substances are present, leading to an indicator color change from purple to yellow. When antimicrobial molecules are present above the detection level, no growth occurs and the color remains purple.

Table I presents the results of the percentage of positive samples in the various regions of Madagascar. On average $37.2 \%$ samples were contaminated by antimicrobial residues. A significant increase from 32 to 39\% was observed between 2010 and 2011,

\section{Tableau I}

Detection of drug residues in pork meat according to the region in Madagascar in 2010 and 2011

\begin{tabular}{lcccccc} 
& \multicolumn{7}{c}{ Region } \\
\hline & Central & North & South & Tana & West & Total \\
\hline $\mathbf{2 0 1 0}$ & & & & & & \\
Sample size & 48 & 10 & 24 & 144 & 54 & 280 \\
Positive (\%) & 46 & 40 & 46 & 25 & 31 & 32 \\
\hline $\mathbf{2 0 1 1}$ & & & & & & \\
Sample size & 162 & NA & 15 & 457 & 53 & 687 \\
Positive (\%) & 39 & NA & 27 & 42 & 23 & 39 \\
\hline
\end{tabular}


respectively. No significant differences were found between samples according to sex, breed or age class in individual animals. No differences between pig farm origins were found either (Figure 1). However, Amoron'i Mania Region, and particularly suburban Ambositra, was the most contaminated area in 2010 $(67 \% ; n=9)$ and Melaky region (Western Madagascar) in 2011. Pork meat samples originating from the same production area were less contaminated by drug residues when the animals were slaughtered in urban abattoirs compared to provincial abattoirs. In this first step toward a national surveillance system, we confirm that drug residues in animal products are a serious public health concern for Madagascar.

\section{REFERENCES}

1. RAKOTOHARINOME M., RANDRIAMPARANY T., POGNON D, CHANE MING J., IDOUMBIN J.P., CARDINALE E., PORPHYRE V., 2014. Prevalence of antimicrobial residues in pork meat in Madagascar. Trop. Anim. Health Prod., 46: 49-55. DOI: 10.1007/s11250-013-0445-9

Accepted 30 April 2015; Online publication June 2015

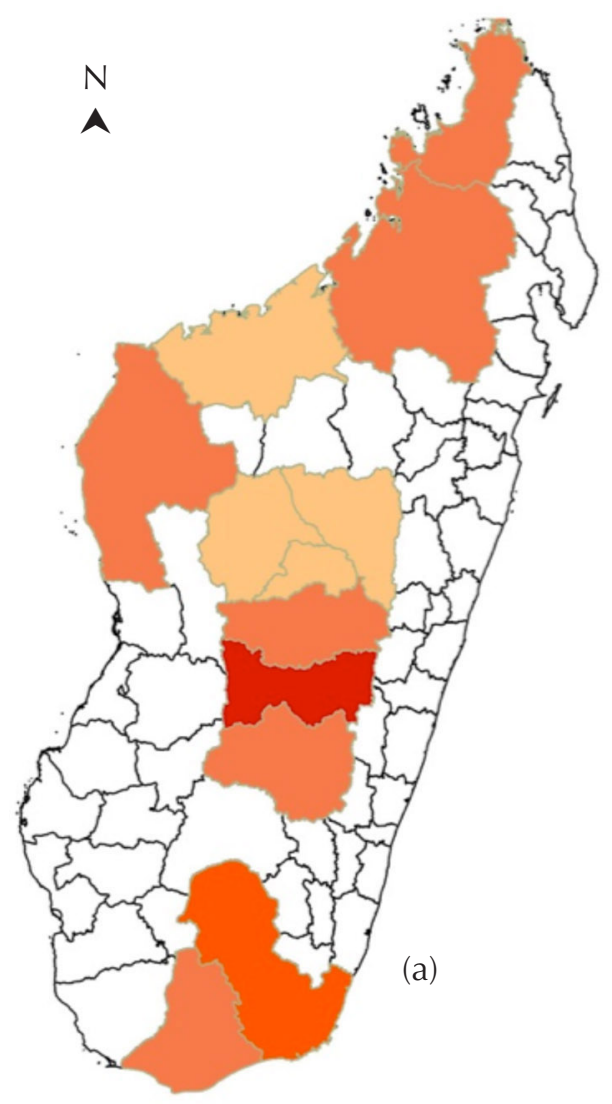

Antibiotic residue prevalence $(\%)$

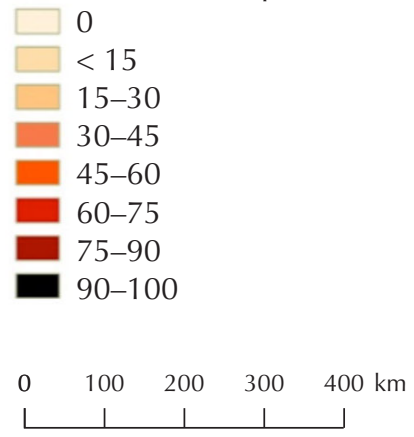

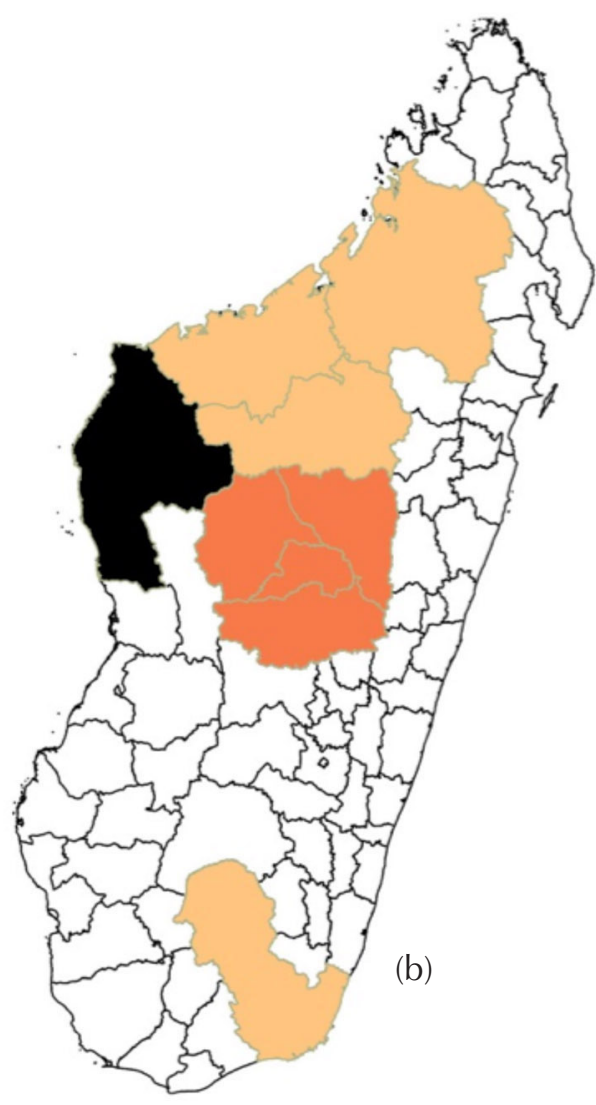

(b)

Figure 1: Distribution maps of antimicrobial-residue-positive samples in pork meat traded in Antananarivo, Madagascar in (a) 2010, and (b) 2011. 